\title{
Gender Stereotype in School: Using Implicit Association Test (IAT) to Investigate Gender-Major Stereotype in Chinese Community
}

\author{
Keying Chen ${ }^{1, *}, \dagger$, Kunpeng Shao ${ }^{2, \dagger}$, Fangtong Wang ${ }^{3, \dagger}$ \\ ${ }^{1}$ Lee Shau Kee School of Business and Administration, Hong Kong Metropolitan University, Hong Kong, China \\ ${ }^{2}$ Nanjing University Business School, Nanjing University, Nanjing, 210093, China \\ ${ }^{3}$ National Institute of Education, Nanyang Technological University, 637616, Singapore \\ ${ }^{*}$ Corresponding author.Email: ${ }^{1}$ s1218264@hkmu.edu.hk \\ These authors contributed equally.
}

\begin{abstract}
Gender stereotype is a phenomenon happening on an everyday basis. Influenced by this biased belief, the common expectation in gender and major is that men are associated with STEM (science, technology, engineering, and mathematics) majors and women are associated with liberal arts majors. Nevertheless, becoming inured to stereotypical thoughts can lead to gender discrimination and polarization. Therefore, to understand individuals' implicit attitudes towards genders and fields of majors, the current study aimed to investigate whether there was a gender stereotype regarding fields of majors in the Chinese community. The Implicit Association Test (IAT) was utilized to examine participants' subconscious responses. Eighteen participants (10 male, 8 female) were recruited, with the age ranging from 20 to 24. They were required to complete a 5-round experiment conducted on PsychoPy. The accuracy rate and reaction time were automatically recorded. The results revealed that participants performed better in the stereotype-congruent condition than in the stereotype-incongruent condition, with their accuracy rate higher and reaction time shorter. In addition, no gender difference was found in either accuracy rate or reaction time. According to the results, we concluded that there was a gender-major stereotype among Chinese young adults and no gender difference was observed.
\end{abstract}

Keywords: Gender stereotype, Implicit Association Test, Chinese.

\section{INTRODUCTION}

It is commonplace to use an exemplar to represent a specific social group according to their mutual characteristics, which is known as a stereotype [1]. Specifically, the intrinsic and dichotomous differences between men and women will lead to stereotypical thinking which places certain expectations on respective genders based on their respective features and traits, social norms, previous knowledge, etc., and this general perception is known as a gender stereotype. Although this categorization is found to be fluid depending on different circumstances and references [2], this fluidity is less likely to happen when it comes to gender categorizations and stereotypes. It is verified that individuals of all ages implicitly clustered unknown subjects by their genders at a relatively high speed $[3,4]$. Overall, previous research has revealed that gender categorizations are instantly perceived, chronically prominent, difficult to alter, and are polarized in most cases [1].

In the educational field, the common belief is that women fit in more expressive and human-concentrated fields while men are suitable in technical-related fields [5]. It is reported by the bulk of studies that math and science are perceived as male domains and masculine traits are attributed to science subjects. For instance, a study reported that only 135 pictures out of 1,600 drawn by students in grades 2 to 12 depicted female scientists, and another study found better performance in STEM (science, technology, engineering, and mathematics) majors was expected to be made by boys among high school students $[6,7]$.

This belief, however, can affect students' major choices and occupational aspirations. Gender 
stereotypes regarding majors will undermine women's self-perceived capability, performance, and interest in STEM majors and hence prevent women from choosing those majors [8]. As a result, their career path will be narrowed and confined to gender-stereotypical vocations, leading to a severer issue of underrepresentation of women in STEM [9] and other masculine fields. The lack of gender diversity in the science and occupational domain will give rise to gender segregation and the wider spread of genderstereotypical beliefs, forming a vicious cycle. Therefore, studying the implicit attitudes regarding gender-major stereotypes presents to be more than significant.

To measure gender-stereotypical beliefs, the Implicit Association Test (IAT) was included in this study. IAT is a tool evaluating individuals' implicit attitudes, which is defined to be judgments and responding actions made by individuals' subconscious minds and automatic evaluation systems [10]. In the IAT experiment, two sets of stimuli representing two target concepts (e.g., American vs. British; wild vs. polite) will be presented to participants both individually and jointly. The comparison between the performance of highly associated stimuli (e.g., American + wild) and that of less associated stimuli (e.g., American + polite) is the experiment focus, which displays differential association of the two concepts [11]. Through the change of combinations of attitude-provoking stimuli, participants' implicit attitudes can be easily captured by monitoring their response performance. It is believed that IAT can reveal implicit attitudes and other subliminal associations between subjects [11]. Therefore, IAT is an appropriate approach to measure participants' implicit attitudes linking gender to major.

Although IAT has been used extensively to measure major-gender stereotypes, previous research focused mainly on STEM majors, and few included liberal art majors. Moreover, the Chinese population seemed to be overlooked in this research field, with the majority of studies investigating American and European populations. Therefore, the purpose of the current study is to measure whether there is a gender-major stereotype among Chinese young adults using IAT, and we hypothesize there is a gender-major stereotype among Chinese young adults. Furthermore, due to previous findings suggesting a weaker implicit gender-math stereotype held by female engineering students compared to that of male humanities students [8], a gender difference is expected from this study, and females are assumed to possess a weaker overall gender-major stereotype.

\section{METHODS}

\subsection{Participants}

Twenty Chinese undergraduates participated in the study. They were recruited from the group members' classmates and friends. Among them, 2 participants were eliminated because they failed to understand the instructions.

Regarding the remaining 18 participants, they were aged 20 to $24(\mathrm{M}=21.00, \mathrm{SD}=1.09)$ with at least an intermediate level of English proficiency. Results of a ttest performed on participants' age indicated that male participants $(\mathrm{M}=20.8, \mathrm{SD}=0.63, \mathrm{n}=10)$ were younger than female participants $(\mathrm{M}=21.25, \mathrm{SD}=1.49, \mathrm{n}=8)$ as a whole, and the age difference was not significant ( $t$ (9) $=-0.80, p=0.44)$. They were all acquiring bachelor's degrees or above in different universities.

All the possible ethical issues throughout the experiment process had been properly considered. Participation was entirely voluntary. The participants could choose to withdraw from the study at any time they wanted without any penalty or negative consequences.

The participants were initially informed that this experiment was a memory test, which wasn't true. After the experiment was completed, the real purpose was revealed to the participants. They were free to regret and drop the data that were collected from them.

\subsection{Materials}

This experiment was conducted on the PsychoPy platform, made up of 5 rounds. Each round consisted of two parts: a memorization task and a categorization task.

The stimuli were all English words including 3 types: gender-specific names (male vs. female), majors (STEM vs. liberal art), and gender-neutral items regarding campus life and study.

In each round, the participants were required to first remember the words and their categorization within a limited time, as illustrated in figure 1.

\begin{tabular}{|c|c|c|c|c|c|c|}
\hline Female & Mary & Emily & Linda & Tina & Emma & Amy \\
\hline Male & Tom & John & Michael & Paul & David & Bob \\
\hline \\
You have 10 seconds to remember as much as you can! \\
\hline
\end{tabular}

Figure 1. Memorization task, sampled from round 1: Initial Name Categorization

The purpose of this part was not exactly to let the participants remember every word, but to familiarize them with the words and which category each belongs to, and to disguise the implicit association test as a memory test.

Then, the participants were required to finish the categorization task with their keyboards. The user interface of this task is illustrated in figure 2. 


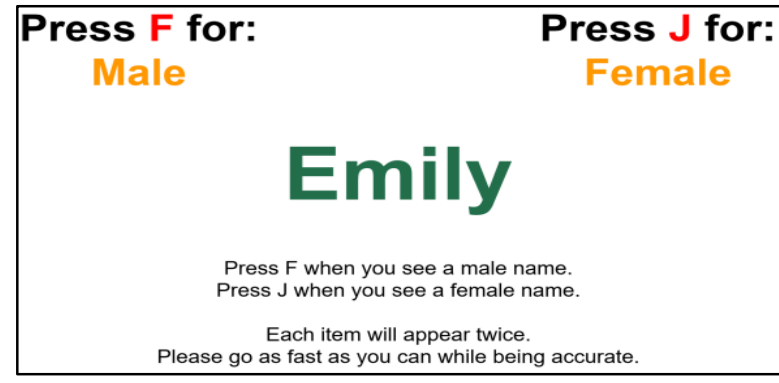

Figure 2. Categorization task, sampled from round 1: Initial Name Categorization

The instruction was at the bottom of the screen. A brief keypress instruction was highlighted at the top of the screen. The stimuli were at the center in another different color. The participants were expected to follow the instruction and press the correct key for each stimulus.

\subsection{Procedure}

\subsubsection{Round 1: Initial Name Categorization}

In the first round, the stimuli were gender-specific names. For example, male names included "Paul" and "David", and female names included "Emma" and "Amy". The participants were given 10 seconds to remember all the names and their categorization, and then they were required to press $\mathrm{F}$ for male names and $\mathrm{J}$ for female names.

The purpose of this round was to familiarize the participants with the names and their correct keys to improve the accuracy in round 3.

\subsubsection{Round 2: Major Categorization}

This round was similar to round 1 . The only difference was that the stimuli were majors. For example, STEM majors included "chemistry" and "mechanics", and liberal art majors included "sociology" and "history". The participants were given 10 seconds to remember all the majors and their categorization, and then they were required to press F for STEM majors and $\mathrm{J}$ for liberal art majors.

\subsubsection{Round 3: Initial Combined Categorization}

This was the first of the two important rounds where the implicit association was expected to be induced. In this round, the stimuli were gender-specific names and majors, along with some new gender-neutral items regarding campus life and study, such as "classroom". The participants were given 5 seconds to remember all the new items, and then they were required to press $\mathrm{F}$ for male names or STEM majors, $\mathrm{J}$ for female names or liberal art majors, and space for new items.

\subsubsection{Round 4: Reversed Name Categorization}

This round was much similar to round 1 . The only difference was that the correct keys for the names categorization were reversed. There was no memorization task. The participants were required to press $\mathrm{F}$ for science and engineering majors and $\mathrm{J}$ for liberal art majors.

The purpose of this round was to familiarize the participants with the reversed correct keys for the names in order so that the interference from round 1 and 3 was reduced, and therefore the accuracy in round 5 was improved.

\subsubsection{Round 5: Reversed Name Categorization}

This round was another important round and was similar to round 3 . The differences are that the correct keys for names categorization were still reversed while the correct keys for majors remained the same and that there were a new set of gender-neutral items. The participants were given 5 seconds to remember all the new items, and then they were required to press $\mathrm{F}$ for female names or STEM majors, J for male names or liberal art majors, and space for new items.

\subsection{Data Analysis}

The dependent variable of this experiment was the participants' performance, which included accuracy and reaction time.

Each participant's key-press accuracy in each round was calculated independently. Then, among the correct key presses of each round, the mean reaction time was calculated. The standard deviation was also calculated to examine the amount of variation and dispersion of the data. The data from round 3 and 5 were focused and compared to measure the variance, which could indicate whether there existed the congruence effect, and hence an implicit association. A t-test was needed to determine the significance of variance of both accuracy and reaction time.

A comparison between the two genders could also be made by performing a t-test based on the accuracy and reaction time of participants of either gender.

\section{RESULTS}

Table 1 and 2 demonstrated relevant descriptive statistics of experimental results. Participants' response accuracy and reaction time (with neutral words) were included. As round 3 and round 5 were considered respectively as the stereotype-congruent condition and the stereotype-incongruent condition, the focus of the analysis was on these two rounds. 
Table 1. Accuracy rate of the participants

\begin{tabular}{llll}
\hline $\begin{array}{l}\text { Accuracy rate } \\
\text { (\%) }\end{array}$ & $\begin{array}{l}\text { Male } \\
\text { M(SD) }\end{array}$ & $\begin{array}{l}\text { Female } \\
M(S D)\end{array}$ & $\begin{array}{l}\text { Total } \\
\text { M(SD) }\end{array}$ \\
\hline Round 1 & $95.41(4.99)$ & $96.35(4.13)$ & $95.83(4.52)$ \\
Round 2 & $95.83(5.20)$ & $92.71(10.14)$ & $94.44(7.70)$ \\
Round3 & $95.00(4.30)$ & $97.92(3.15)$ & $96.30(4.01)$ \\
(without NW) & & & \\
Round 4 & $97.09(3.43)$ & $98.44(2.16)$ & $97.68(2.94)$ \\
Round5 & $86.67(6.46)$ & $86.46(23.01)$ & $86.57(15.50)$ \\
(without NW) & & & \\
NW (overall) & $98.33(3.51)$ & $94.80(6.20)$ & $96.76(5.06)$ \\
\hline
\end{tabular}

Note: NW represents neutral words; NW (overall) stands for neutral words in round 3 and round 5 overall.

A t-test revealed a statistically significant difference between the accuracy rate of round $3(\mathrm{M}=96.30, \mathrm{SD}=$ $4.01)$ and round $5(\mathrm{M}=86.57, \mathrm{SD}=15.50)$, with both rounds' neutral words excluded $(\mathrm{t}(19)=2.58, \mathrm{p}=0.01)$. A higher accuracy rate in round 3 was observed. In addition, in round 3 , the difference between accuracy rate of male participants $(\mathrm{M}=95.00, \mathrm{SD}=4.30)$ and female participants $(M=97.92, S D=3.15)$ were found to be non-significant $(\mathrm{t}(16)=-1.66, \mathrm{p}=0.12)$. Similarly, the difference in accuracy rate in round 5 between male participants $(\mathrm{M}=86.67, \mathrm{SD}=6.46)$ and female participants $(\mathrm{M}=86.46, \mathrm{SD}=23.01)$ was not significant $(\mathrm{t}(8)=0.02, \mathrm{p}=0.98)$. Therefore, no gender difference was observed in the accuracy rate in round 3 and round 5 .

Table 2. Reaction time of the participants

\begin{tabular}{|c|c|c|c|}
\hline \multirow[t]{2}{*}{ Reaction time (s) } & Male & Female & Total \\
\hline & $M(S D)$ & $M(S D)$ & $M(S D)$ \\
\hline Round 1 & $1.34(4.05)$ & $1.16(0.86)$ & $1.12(0.72)$ \\
\hline Round 2 & $1.10(0.48)$ & $1.37(1.20)$ & $1.23(0.90)$ \\
\hline Round3 (without & $1.38(1.02)$ & $1.41(1.14)$ & $1.36(0.92)$ \\
\hline \multicolumn{4}{|l|}{ NW) } \\
\hline Round 4 & $1.24(0.96)$ & $1.06(0.85)$ & $1.11(0.72)$ \\
\hline Round5 (without & $1.64(0.84)$ & $1.77(1.33)$ & $1.71(1.10)$ \\
\hline \multicolumn{4}{|l|}{ NW) } \\
\hline NW (overall) & $1.38(0.64)$ & $1.33(1.14)$ & $1.38(0.91)$ \\
\hline
\end{tabular}

Note: NW represents neutral words; NW (overall) stands for neutral words in round 3 and round 5 overall.

Reaction time in round $3(\mathrm{M}=1.36, \mathrm{SD}=0.92)$ and round $5(\mathrm{M}=1.71, \mathrm{SD}=1.10)$, with neutral words excluded, was found to be significantly different ( $\mathrm{t}$ (694) $=-4.64, \mathrm{p}=0.00)$, indicating the reaction time in round 3 was significantly shorter than that in round 5 . Besides, the difference between male and female participants in reaction time in round $3(\mathrm{t}(379)=0.31, \mathrm{p}=0.75)$, and round $5(\mathrm{t}(265)=1.11, \mathrm{p}=0.27)$ was not significant, suggesting no gender difference in reaction time between round 3 and round 5 .

\section{DISCUSSION}

The current study investigated the gender stereotypes regarding majors among Chinese young adults. We employed the IAT and expected a difference in participants' performance between the stereotypecongruent condition and the stereotype-incongruent condition, and a difference in the overall performance of participants of different genders.

This study supports our hypothesis that majorgender stereotypes exist among Chinese young adults. As shown in results, a statistically significant difference between the accuracy of round 3 and round 5 (with both rounds' neutral words excluded) was shown. Participants performed worse in the stereotypeincongruent condition than that in the stereotypecongruent condition. This result is consistent with previous findings that suggested a gender bias in people when processing different fields of majors $[6,7]$.

Nevertheless, there was no evidence of a statistically significant gender difference in accuracy rate and reaction time, contradicting our initial hypothesis proposing a weaker overall gender-major stereotype in women. This finding is inconsistent with previous research that displayed female engineering students held weaker implicit gender math and gender-reasoning stereotypes than female humanities, male engineering, and male humanities students [8]. Similarly, another research demonstrated that about $70 \%$ of more than half a million Implicit Association Tests completed by citizens of 34 countries revealed expected implicit stereotypes associating science with males more than with females [12].

Other than direct gender difference, there was an article showing that the gender gap in students' math performance is substantially affected by teachers' implicit stereotypes [13]. Girls, especially those with lower initial skills, are lagging when assigned to teachers with stronger math male and literature-female implicit associations. Boys, the group not abilitystigmatized in terms of math performance, are not affected by teacher stereotypes. This study gave us some insights about the origin of gender-major stereotype.

Certain limitations were presented in order to help improving future research. One limitation was that, when selecting participants, only the difference of gender was considered rather than the difference of fields of majors. Participants' majors might affect their understanding of the majors presented in the experiment, as in whether they belonged to STEM or liberal art, which could result in hesitance and errors. Another limitation was that the selection range and the number of samples were very limited. The intended participants were Chinese young adults. However, only 20 individuals were recruited, and the majority of them were at school receiving higher education and had at 
least an intermediate English level, who could not optimally represent the population of Chinese young adults. It was likely that our participants had very similar thoughts and cognition, thus give rise to the unconvincing results. Furthermore, due to the nature of Internet-based experiment, the external environment, the mental and physical status of participants, and the devices which participants used were not strictly controlled, any of which could disturb participants and lead to different results. Finally, the interference from the initial three rounds in the reversed two rounds was difficult to determine. It was observed that during the experiment many participants were familiarized with the initial key arrangement for gender-specific names and felt difficult to perform the reversed tasks, which is a natural psychological phenomenon.

Overall, despite the suggested limitations, our studies provided some compelling evidence for the existence of major-gender stereotypes. The main findings of the study can be applied to real-life settings. For instance, educators are supposed to learn from the study and avoid basing their presumptions of whether students can learn a course well simply on their gender; parents are advised to stop imposing their ideas of suitable major and career goals upon their children only according to gender stereotypes. We look forward to seeing this study play a role in both academic and public discourses on Chinese feminism.

The limitations of this study hopefully can inspire future research. It is expected that in future research, a questionnaire should be delivered to participants prior to the experiment in order to make the grouping of participants more detailed. Also, future researchers can improve the diversity of the participants, for example, provide a Chinese version of experiment and recruit Chinese youth from different occupations and educational backgrounds besides university students. In addition, future researchers should consider the potential influence of the interference effect, for example, set a comparison group of participants who perform the stereotype-incongruent condition first.

\section{CONCLUSION}

This study filled the gap of research on majorgender stereotypes among Chinese young adults. In the IAT, the participants performed worse in the stereotypeincongruent condition than that in the stereotypecongruent condition. An implicit gender-major stereotype was thus revealed where men were associated with STEM majors and women were associated with liberal art major. The performance of male and female participants showed no evidence for significant difference in the extent of stereotype between both genders. The main findings can be meaningful for future sociology and psychology researchers to base their study on or further examine the gender differences in gender stereotypes. Educators and educational institutions in China need to take notice of this study to reduce the impact of major-gender stereotypes and promote gender equality. Employers should also be concerned and improve gender diversity in the workplace. With this study, more public awareness of the gender biases shall be raised in support of the gender equality and feminist movement in China.

\section{REFERENCES}

[1] Ellemers, N. (2018). Gender Stereotypes. Annual Review of Psychology, 69, 275-298. DOI: https://doi.org/10.1146/annurev-psych-122216011719

[2] Oakes, P. J., Haslam, S. A., \& Turner, J. C. (1994). Stereotyping and Social Reality. Oxford, UK: Blackwell.

[3] Bennett, M., Sani, F., Hopkins, N., Agostini, L., \& Malucchi, L. (2000). Children's gender categorization: an investigation of automatic processing. British Journal of Developmental Psychology, 18(1), 97-102. DOI: https://doi.org/10.1348/026151000165599

[4] Ito, T. A., \& Urland, G. R. (2003). Race and gender on the brain: electronic measures of attention to the race and gender of multiply categorizable individuals. Journal of Personality and Social Psychology, 85(4), 616-626. DOI: https://doi.org/10.1037/0022-3514.85.4.616

[5] Makarova, E., Aeschlimann, B., \& Herzog, W. (2019). The gender gap in STEM fields: The impact of the gender stereotype of math and science on secondary students' career aspirations. Frontiers in Education, 4, 60. DOI: https://doi.org/10.3389/feduc.2019.00060

[6] Fort, D. C., \& Varney, H. L. (1989). How students see scientists: mostly male, mostly white, and mostly benevolent. Science and Children, 26, 8-13.

[7] Hand, S., Rice, L., \& Greenlee, E. (2017). Exploring teachers' and students' gender role bias and students' confidence in STEM fields. Social Psychology of Education, 20, 929-945. DOI: https://doi.org/10.1007/s11218-017-9408-8

[8] Smeding, A. (2012). Women in science, technology, engineering, and mathematics (STEM): An investigation of their implicit gender stereotypes and stereotypes' connectedness to math performance. Sex roles, 67(11), 617-629. DOI: https://doi.org/10.1007/s11199-012-0209-4

[9] National Science Foundation. (2009). TABLE C-4. Bachelor's degrees, by sex and field: 1997-2006. 
Retrieved

http://www.nsf.gov/statistics/wmpd/tables.cfm.

[10] Greenwald, A. G., \& Banaji, M. R. (1995). Implicit social cognition: Attitudes, self-esteem, and stereotypes. Psychological Review, 102, 4-27.

[11] Greenwald, A. G., McGhee, D. E., \& Schwartz, J. L. (1998). Measuring individual differences in implicit cognition: the implicit association test. Journal of personality and social psychology, 74(6), 1464.
[12] Nosek, B. A., Smyth, F. L., Sriram, N., Lindner, N. M., Devos, T., Ayala, A., ... \& Greenwald, A. G. (2009). National differences in gender-science stereotypes predict national sex differences in science and math achievement. Proceedings of the National Academy of Sciences, 106(26), 10593 10597.

[13] Carlana, M. (2019). Implicit stereotypes: Evidence from teachers' gender bias. The Quarterly Journal of Economics, 134(3), 1163-1224. 